\title{
BMJ Open Changes in the rate of publicly financed knee arthroscopies: an analysis of data from the Norwegian patient registry from 2012 to 2016
}

\author{
Robin Holtedahl, ${ }^{1}$ Jens Ivar Brox,${ }^{2,3}$ Arne Kristian Aune, ${ }^{4}$ Daniel Nguyen, ${ }^{5}$ \\ May Arna Risberg, ${ }^{6}$ Ole Tjomsland ${ }^{5}$
}

To cite: Holtedahl R, Brox Jl, Aune AK, et al. Changes in the rate of publicly financed knee arthroscopies: an analysis of data from the Norwegian patient registry from 2012 to 2016. BMJ Open 2018;8:e21199. doi:10.1136/ bmjopen-2017-021199

- Prepublication history and additional material for this paper are available online. To view these files, please visit the journal online (http://dx.doi org/10.1136/bmjopen-2017021199).

Received 16 December 2017 Revised 10 April 2018 Accepted 18 May 2018
Check for updates

${ }^{1}$ Department of Habilitation and Rehabilitation, Innlandet Hospital Trust-Division Ottestad, Ottestad, Norway

${ }^{2}$ Department of Physical Medicine and Rehabilitation, Oslo University Hospital, Oslo, Norway

${ }^{3}$ Medical Faculty, University of Oslo, Oslo, Norway

${ }^{4}$ Orthopaedic Department, Aleris Hospital, Drammen, Norway

${ }^{5}$ South-Eastern Norway Regional Health Authority, Hamar, Norway

${ }^{6}$ Department of Sports Medicine, Norwegian School of Sport

Sciences, Oslo, Norway

Correspondence to

Dr. Robin Holtedahl; robi-hol@online.no

\section{ABSTRACT}

Objective To examine rates of publicly financed knee arthroscopic surgery in Norway between 2012 and 2016. Design Analysis of anonymised data from the National Patient Registry.

Interventions Beginning in 2012, South-Eastern Norway Regional Health Authority implemented administrative measures to bring down rates of knee arthroscopy. Similar measures were not introduced in the other three Regional Health Authorities.

Main outcome measures We analysed annual national rates of publicly financed knee arthroscopies in 2012 and 2016. We compared the rates in South-Eastern Norway Regional Health Authority with corresponding rates in the rest of the country. Variations by county, public hospital versus publicly reimbursed private hospital, gender and age were also assessed.

Results The overall annual rate of arthroscopic procedures declined by $33 \%$ from 2012 to 2016 , from 310 to 207 per 100000 inhabitants, respectively. Hospitals in South-Eastern Norway Regional Health Authority reported a $48 \%$ reduction, compared with mean $13 \%$ in the other three Regional Health Authorities. In public hospitals, rates decreased nationally by $42 \%$, while rates in publicly reimbursed private hospitals increased by $12 \%$. Rates in publicly reimbursed private hospitals decreased by $30 \%$ in South-Eastern Norway Regional Health Authority but increased by $63 \%$ in the other Regional Health Authorities. The proportion of patients $\geq 50$ years (excluding meniscal repairs) in Norway was 54\% in 2012 and fell to $46 \%$ in 2016. Average rates per county varied by a factor of 3:1. Conclusion We report a marked overall reduction of knee arthroscopic procedures from 2012 to 2016 in publicly funded hospitals. The largest decrease was reported in South-Eastern Norway Regional Health Authority, and this coincides in time with implemented administrative measures. The results suggest that the trend of increasing rates of knee arthroscopies can be reversed through purposeful professional and administrative interventions.

\section{INTRODUCTION}

Therapeutic knee arthroscopy has become the most commonly performed outpatient orthopaedic procedure in most countries

\section{Strengths and limitations of this study}

- We consider the data reliable because reporting to the National Patient Registry is a requirement for public reimbursement.

- Diagnoses were not registered, and the study period was limited to 5 years.

Rates of knee arthroscopy in private hospitals without reimbursement by public healthcare are not available.

with available data, including Norway. Joint debridement and lavage for osteoarthritis and meniscal resection or repair for meniscal lesions are the most commonly performed procedures. The increasing rates have been especially pronounced in middle-aged and elderly patients. ${ }^{1}$ However, evidence of radiologically verified degenerative changes, including meniscal tears, are common in this age group, even in those without knee pain or history of knee injury. ${ }^{2}{ }^{3}$ Large regional variations of knee arthroscopy have also been described. ${ }^{4}$ Several randomised controlled trials published during the last decades have been unable to demonstrate superiority of arthroscopic procedures over a sham procedure $^{5}$ or supervised physiotherapy. ${ }^{6-11}$ These results have led to a critical reappraisal of these procedures, including recent systematic reviews and guidelines advising against arthroscopy as a first line of treatment for degenerative knee disorders. ${ }^{12-14}$

Of the four Regional Health Authorities in Norway, South-Eastern Norway Regional Health Authority is the largest, and responsible for secondary health services for more than half the Norwegian population. In 2012, South-Eastern Norway Regional Health Authority initiated a process aiming to reduce the volume of publicly financed arthroscopic procedures and unwarranted 
regional variations. In joint meetings with the chief medical officers in the region and the Division of Orthopaedic Surgery, Oslo University Hospital, results of recent studies of arthroscopic procedures for degenerative meniscal tears and osteoarthritis were discussed, and also distributed to the chief medical officers at private hospitals with reimbursement contracts in the region. In 2015, South-Eastern Norway Regional Health Authority adjusted the terms for the contracts with the public and private providers, requiring that the proportion of treated patients above the age of 50 years did not exceed $20 \%$, and that physical therapy should be tried for at least 3 months prior to surgery. Similar measures were not introduced in the other Regional Health Authorities.

The aims of this study are to estimate overall time trends in knee arthroscopy rates in Norway from 2012 to 2016, and to elucidate possible associations between observed changes and administrative or professional incentives.

\section{METHODS}

\section{Subjects and procedures}

We extracted anonymised data from Norwegian Patient Registry on arthroscopic knee procedures in public hospitals and private hospitals with reimbursement contracts between 2012 and 2016. Private hospitals operating on contract with the regional trust are hereafter denoted 'private hospitals'. Procedures not reimbursed by the public health system were not included. The procedures were debridement for osteoarthritis (code NGF31), meniscal repair (NGD21) and meniscal resection (NGD11) as defined by Nomesco Classification of Surgical Procedures. Only the primary procedure was registered. The rates of knee arthroscopies were based on the number of individual procedures, not patients. We did not obtain diagnoses of the patients, and the proportion of traumatic versus atraumatic cases is not known. Patients younger than 10 years were excluded. We analysed age-adjusted rates per county based on population statistics from Statistics Norway (https://www.ssb.no/ en/), the number of procedures done in public hospitals versus private hospitals, time trends in total rates, regional variations and rates per age group and sex. Correlations between arthroscopy rates in public and private hospitals per county were analysed.

\section{Ethics and statistics}

This study included only anonymous data extracted from the Norwegian Patient Registry. Approval of access to the registry was obtained from the National Data Inspectorate. Differences in arthroscopy rates across gender and hospital provider type were analysed using $\chi^{2}$ test. D'Agostino-Pearson test was used to test for normal distribution. Unpaired non-parametric data were analysed using the Mann-Whitney U test. Associations between rates in public versus private hospitals per county were assessed using Pearson correlation coefficient. Analyses were performed using Medcalc V.17.9.7 (www.medcalc.org).

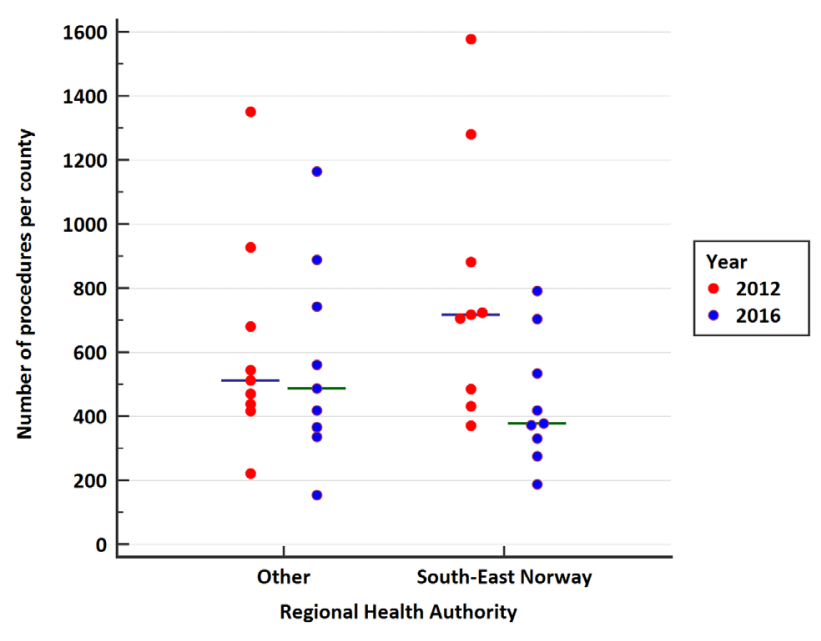

Figure 1 Number of knee arthroscopies per county in South-Eastern Norway Regional Health Authority in 2012 and 2016 versus other Regional Health Authorities. Each dot represents a county. Horizontal bars represent medians.

\section{Patient and public involvement}

Patients or public were not involved in this study.

\section{RESULTS}

From 2012 to 2016, 66901 arthroscopic procedures were performed in public and private hospitals for meniscal lesions and osteoarthritis. A total of 13652 procedures were performed in 2012, increasing to 16157 in 2013 and decreasing to 9543 in 2016. The rate of procedures per 100000 was 310 in 2012 and 207 in 2016, a reduction of $33 \%$. In the 10 counties in South-Eastern Norway Regional Health Authority, the overall rate in this period decreased from 325 to 171 per 100000 (48\%). In the remaining nine counties, the overall rate decreased from 290 to 253 per 100000 (13\%). The corresponding median rate reductions per county were $46 \%$ (CI from $41.2 \%$ to $49.6 \%$ ) and $5 \%$ (CI $-20.6 \%$ to $30.4 \%$ ), respectively. Figure 1 shows the number of procedures per county in South-Eastern Norway Regional Health Authority compared with the other Regional Health Authorities in 2012 and 2016. Online supplementary figure 1 shows the number of procedures per Regional Health Authority in 2012 and 2016.

$22664(34 \%)$ of all knee arthroscopies in the study period were performed in private hospitals, in which there nationally were 2943 procedures in 2012 and 3293 in 2016 , an increase of $12 \%$. In public hospitals, the corresponding numbers were 10709 and 6250, a 42\% reduction $(\mathrm{p}<0.0001$ for difference public vs private hospitals). In private hospitals in South-Eastern Norway Regional Health Authority, there was a $30 \%$ reduction in mean rate per 100000 in the study period, from 62 to 43 , while there was an increase of $63 \%$ in private hospitals in the remaining Regional Health Authorities, from 67 to 109 ( $\mathrm{p}=0.0008$ for difference between the Regional Health Authorities). In public hospitals in South-Eastern 
Table 1 Number, rate and rate change of all knee arthroscopies in 2012 and 2016 per Regional Health Authority (RHA), public and private hospitals

\begin{tabular}{|c|c|c|c|c|c|}
\hline & \multicolumn{2}{|c|}{ Number of procedures } & \multicolumn{2}{|c|}{ Rate per 100000} & \multirow{2}{*}{$\begin{array}{l}\text { Rate change } \\
2012-2016(\%)\end{array}$} \\
\hline & 2012 & 2016 & 2012 & 2016 & \\
\hline All regions/hospitals & 13652 & 9543 & 310 & 207 & -33 \\
\hline South-East RHA & 8024 & 4421 & 326 & 171 & -48 \\
\hline Other RHAs* & 5628 & 5122 & 290 & 253 & -13 \\
\hline All public hospitals & 10709 & 6250 & 243 & 136 & -42 \\
\hline All private hospitals & 2943 & 3293 & 67 & 71 & 12 \\
\hline Public hospitals South-East RHA & 6430 & 3306 & 248 & 128 & -49 \\
\hline Public hospitals other RHAs & 4279 & 2944 & 212 & 146 & -31 \\
\hline Private hospitals South-East RHA & 1594 & 1115 & 62 & 43 & -30 \\
\hline Private hospitals other RHAs & 1349 & 2178 & 67 & 109 & 63 \\
\hline
\end{tabular}

*West, Mid-Norway and North Regional Health Authorities.

Norway Regional Health Authority, there was a decrease of $49 \%$, from mean rate 248 to 128 per 100000 , while there was a decrease of $31 \%$ in the remaining Regional Health Authorities, from 212 to 146 ( $\mathrm{p}=0.07$ for difference) (table 1).

Meniscal procedures comprised about $85 \%$ of all knee arthroscopies throughout the study period. The overall rate of meniscal resections fell from 256 to 156 per 100 000, a $36 \%$ reduction. In public hospitals, there was a $48 \%$ reduction, whereas there was a $7 \%$ increase in private hospitals $(\mathrm{p}<0.0001$ for difference public vs private). The overall rate of meniscal repairs increased from 11 to 23 per $100000,87 \%$ of which were performed in public hospitals. Cartilage debridement rates decreased overall from 44 to 29 per 100000 , with a $45 \%$ reduction in public hospitals but a $16 \%$ increase in private hospitals ( $<<0.0001$ for difference) (table 2).

The proportion of patients 50 years or older having meniscal resection and debridement in the study period fell from $54 \%$ to $44 \%$ in public hospitals in South-Eastern Norway Regional Health Authority, from 53\% to $48 \%$ in public hospitals in the other Regional Health Authorities and from $58 \%$ to $48 \%$ in private hospitals in all regions ( $\mathrm{p}=0.9$ for differences) (figure 2, table 2). For meniscal repairs, the proportion of patients 40 years or older increased nationally from 13\% to $19 \%$ in the study period (table 2). Rates of meniscal resections nationally were reduced by $24 \%$ in patients younger than 50 years and by $46 \%$ in patients 50 years or older in the study period ( $<<0.0001$ for difference between age groups) (figure 3 ). The corresponding reductions for debridement were $26 \%$ and $36 \%(\mathrm{p}=0.04)$ (table 2$)$.

The percentage of males having knee arthroscopy in the study period was on average $60 \%$. The male preponderance was more pronounced in the younger age groups ( $65 \%$ males $<50$ years vs $54 \%$ males $\geq 50$ years). For males, arthroscopy rates decreased by $44 \%$ and for females by $39 \%$ in the study period ( $\mathrm{p}=0.0009$ for sex difference). In 2016, males comprised $62 \%$ of meniscal resections and repairs whereas debridements were performed at approximately similar rates for males and females (table 2).

The age-adjusted average rates of arthroscopies per county of residence in 2016 ranged from 119 to 391 per 100000 . There were also large variations in the contribution of private hospitals to overall arthroscopic rates per county, ranging from $7 \%$ to $69 \%$ (figure 4 ). There was a moderate positive correlation $(\mathrm{r}=0.47)$ between the rate of arthroscopies performed in public and private hospitals per county.

\section{DISCUSSION}

Using data from the Norwegian National Registry, this study found that knee arthroscopy rates nationally decreased by $33 \%$ from 2012 to 2016. The reductions varied by region, with hospitals in South-Eastern Norway Regional Health Authority reporting a 48\% reduction compared with $13 \%$ in the other regions. Public hospitals reported a 42\% reduction from 2012 to 2016, whereas private hospitals reported a $12 \%$ increase.

Reporting of data to the Norwegian Patient Registry is a precondition for reimbursement, and the figures presented are likely to represent a reliable estimate of the actual number of arthroscopic procedures in this 5-year period. Coding practices may vary between hospitals, and we cannot exclude recording errors. We did not differentiate between traumatic and non-traumatic disorders, and we have no information about clinical diagnosis or concomitant procedures (for instance if debridement was performed in conjunction with meniscal resection). Due to restrictions from the National Data Inspectorate, we were not able to obtain data prior to 2012, which precludes the possibility of viewing the rates in a longer time perspective.

Another limitation is the lack of publicly available information about the volume of knee arthroscopies performed by surgical units without public reimbursement contracts, even though compulsory reporting from these clinics to 
Table 2 Number and proportion of meniscal resections, meniscal repairs and debridement by sex, age group, Regional Health Authority (RHA), public and private hospitals in 2012 and 2016

\begin{tabular}{|c|c|c|c|c|c|c|}
\hline & \multicolumn{2}{|c|}{ Meniscal resection } & \multicolumn{2}{|c|}{ Meniscal repair } & \multicolumn{2}{|c|}{ Debridement } \\
\hline & 2012 & 2016 & 2012 & 2016 & 2012 & 2016 \\
\hline \multicolumn{7}{|l|}{ Sex, number $(\%)^{*}$} \\
\hline Males & $7181(60)$ & $4482(62)$ & $358(66)$ & $648(62)$ & $1950(54)$ & $677(51)$ \\
\hline Females & $4859(40)$ & $2691(38)$ & $184(34)$ & $401(38)$ & $1633(46)$ & $652(49)$ \\
\hline \multicolumn{7}{|l|}{ Age group, number (\%) } \\
\hline $10-19$ & $301(3)$ & $343(5)$ & $155(32)$ & $289(28)$ & $70(4)$ & $71(5)$ \\
\hline $20-29$ & $722(6)$ & $719(10)$ & $180(37)$ & 334 (32) & $156(8)$ & $134(10)$ \\
\hline $30-39$ & $1286(11)$ & $939(13)$ & $86(18)$ & $224(21)$ & $261(14)$ & $164(12)$ \\
\hline $40-49$ & $2734(24)$ & $1842(26)$ & $47(10)$ & $149(14)$ & $451(23)$ & $326(25)$ \\
\hline $50-59$ & $3117(28)$ & $1849(26)$ & $12(2)$ & $45(4)$ & $530(28)$ & $342(26)$ \\
\hline $60-69$ & $2313(21)$ & $1072(15)$ & $4(1)$ & $6(1)$ & $350(18)$ & $210(16)$ \\
\hline $70-79$ & $674(6)$ & $372(5)$ & - & - & $96(5)$ & $78(6)$ \\
\hline $80+$ & $106(1)$ & $37(1)$ & - & - & $13(1)$ & $4(0.3)$ \\
\hline \multicolumn{7}{|c|}{ Patients $\geq 50$ by hospital type and region (\%) } \\
\hline Public, South-East RHA & 59 & 46 & - & 4 & 52 & 56 \\
\hline Public, other RHAs & 54 & 46 & 4 & 6 & 53 & 34 \\
\hline Private (all RHAs) & 54 & 48 & 4 & 3 & 50 & 47 \\
\hline \multicolumn{7}{|c|}{ Hospital type and region, number (\%) } \\
\hline Public, South-East RHA & $5531(50)$ & $2426(34)$ & $281(58)$ & $615(59)$ & $653(23)$ & $298(39)$ \\
\hline Public, other RHAs & $3157(28)$ & $2114(29)$ & $205(42)$ & $295(28)$ & $822(34)$ & $508(23)$ \\
\hline Private, South-East RHA & $1515(13)$ & $978(14)$ & - & $76(7)$ & $79(4)$ & $60(4)$ \\
\hline Private, other RHAs & $976(9)$ & $1653(23)$ & - & $63(6)$ & 373 (19) & 463 (34) \\
\hline Sum annual procedures & $11253(100)$ & $7173(100)$ & $486(100)$ & $1049(100)$ & $1927(100)$ & $1329(100)$ \\
\hline
\end{tabular}

*Values for '2012' refer to 2013.

the Norwegian Patient Registry has recently been called for. Voluntary health insurance has played an increasing role in Norwegian healthcare, with approximately a

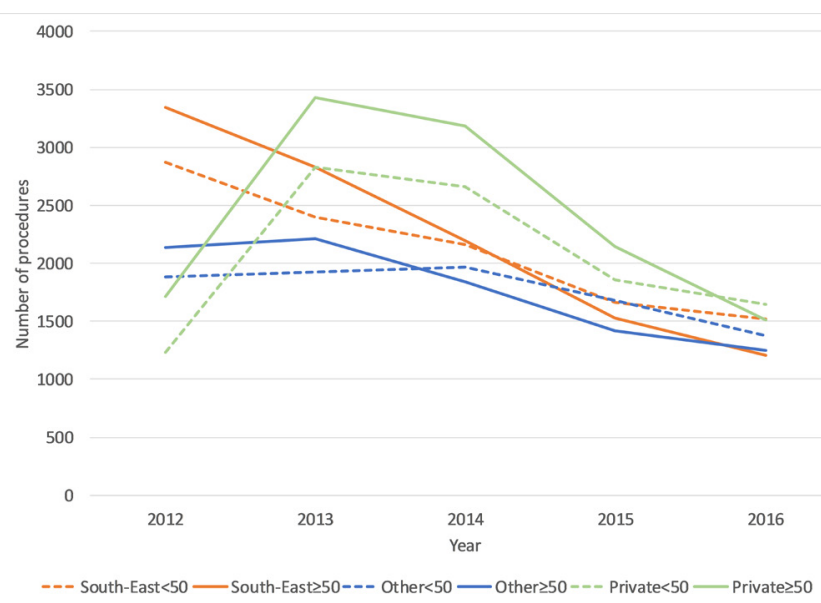

Figure 2 Number of meniscal resections and debridement for ages $<50$ and $\geq 50$ in public hospitals in South-Eastern Norway Regional Health Authority, public hospitals in other Regional Health Authorities and all private hospitals with reimbursement contracts. 12-fold increase in the number of insured persons during the last decade. By 2015, almost 500000 persons (1/10 of the population) were covered, with $95 \%$ of the expenses carried by employer. In addition, some procedures are financed through out-of-pocket payments. The Regional Health Authorities have no financial or administrative role in privately financed surgical services.

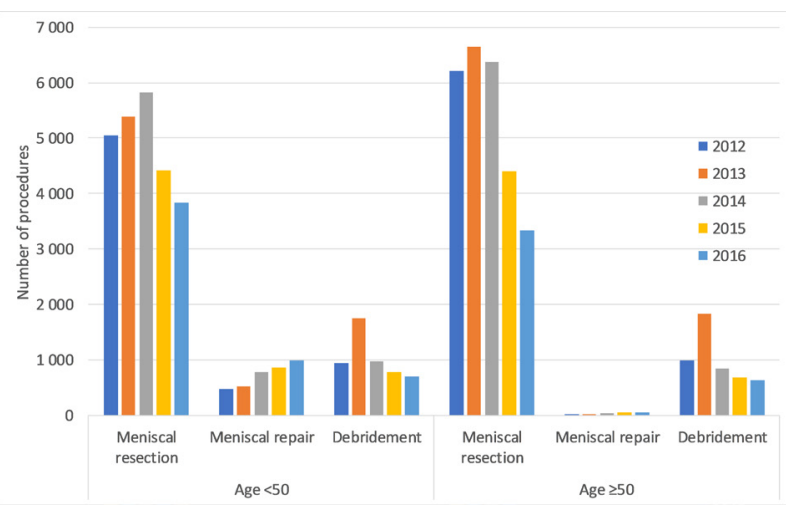

Figure 3 Number of meniscal resections, meniscal repairs and debridement per year for ages $<50$ and $\geq 50$. All Regional Health Authorities, public and private hospitals. 


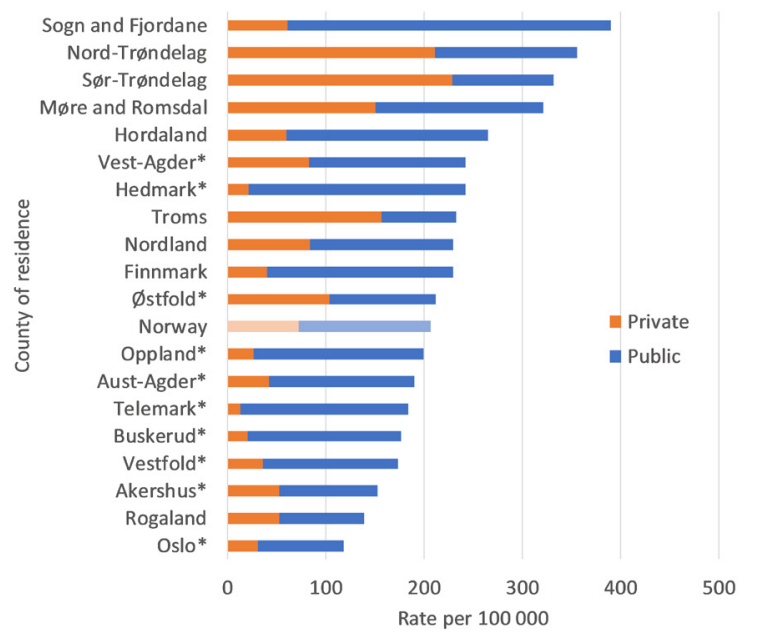

Figure 4 Age-adjusted annual rates of knee arthroscopy per 100000 in 2016 per county of residence, public and private hospitals. *Counties in South-Eastern Norway Regional Health Authority.

Other authors have reported increases in knee arthroscopy rates, especially meniscal resections, since the $1990 \mathrm{~s}^{115-17}$ though this is not invariably the case. ${ }^{1618} 19$ There is limited evidence of more recent trends. Comparisons between studies are challenging due to varying coding procedure practices and differences in health insurance. A Swiss study of patients aged $>40$ years reported a $9 \%$ reduction in knee arthroscopy rates, from 388 to 352 per 100000 between 2012 and 2015, with no described administrative or political regulations. ${ }^{20}$ Finland, Denmark and Sweden have publicly accessible databases which all use the Nomesco classification and include privately financed procedures (sampo.thl.fi, sundhedsstyrelsen.dk and socialstyrelsen.se, respectively). From 2012 to 2016, arthroscopy rates per 100000 in Sweden decreased from 206 to 157 (24\%), in Denmark from 290 to $183(37 \%)$ and in Finland from 339 to 187 (52\%). These reductions have reportedly taken place without any administrative regulations. From 2017, arthroscopic procedures for degenerative knee conditions are no longer included in publicly funded healthcare services in Finland.

In spite of the decreases in arthroscopy rates in Norway since 2013, rates in 2016 were still higher than in Denmark, Sweden and Finland. One noteworthy finding in the present study is the divergence of rates in South-Eastern Regional Health Authority versus rates in other regions, as well as in public versus private hospitals nationally. It is tempting to attribute the described reductions in both public and private hospitals in SouthEastern Norway Regional Health Authority to the recommendations and more restrictive contract terms in the period 2012-2015, though it is prudent to emphasise that secular associations do not equate with causality.

Despite the described overall reductions, knee arthroscopies are still performed more often than justified based on recent high-quality research and evidence-based clinical practice guidelines. ${ }^{14}$ This is especially relevant for the middle-aged and older age groups, where degeneration plays a major role. The requirement in the most recent bids from South-Eastern Norway Regional Health Authority is that at most $20 \%$ of operated patients should be $>50$ years. This is based on evidence showing that practically all patients in this age group have complaints that are not expected to benefit from arthroscopic procedures. ${ }^{12} 13$ The proportion of older to younger patients was only reduced by seven percentage points in the same period which supports the need for stronger regulation of reimbursement. If the $80 / 20$ rule had been implemented as required, about 2300 fewer arthroscopies would have been performed in 2016 (excluding meniscal sutures).

The large differences in arthroscopy rates per county are unlikely to be explained by medical factors. Factors at the administrative level (ie, differing influences and involvement by the Regional Health Authorities), varying attitudes and traditions among the referring general practitioners and orthopaedic surgeons and different access to evidence-based conservative management may play a role. $^{21}$ The positive per-county correlation between rates in public and private hospitals suggests that the private sector contributes to the variability of rates across counties. A supply-sensitive model may be more appropriate to explain this than a demand-sensitive model. ${ }^{21}$ Instead of compensating for deficiencies in the public sector, the private hospitals seem to drive up overall rates even in counties with adequate capacities in public hospitals. Increasing arthroscopy rates in private hospitals have also been reported from Denmark and Australia. ${ }^{42}$ Financial incentives are likely to influence surgical rates, especially in the private sector. ${ }^{20} 23$

The approach to the treatment of degenerative knee disorders could be described as preference sensitive, in that there has not traditionally been a clear consensus on how this group should be managed. Beliefs about the need for surgery in order to recover from a meniscal 'injury' as well as overoptimistic expectations of postoperative function and recovery have most likely contributed to the popularity of knee arthroscopy during the last two decades. ${ }^{24}$ Improving patients' and healthcare providers' knowledge about evidence-based medicine is likely to reduce demand for knee surgery. ${ }^{25}$ Inspired by recent randomised trials showing that arthroscopic procedures are not more effective than supervised physiotherapy in alleviating pain and improving function in patients with degenerative meniscal disorders, national models for implementation of evidence-based guidelines for treatment of degenerative meniscus tears, early and moderate knee and hip osteoarthritis were established in Denmark (GLAD: www.glaid.dk) and Sweden (BOA: https://boa.registercentrum.se). ${ }^{26}$ Similar national models were established in Norway in 2015 through a treatment programme named AktivA (www.aktivmedartrose.no). 


\section{CONCLUSIONS}

Rates of publicly funded arthroscopic knee procedures in Norway decreased overall by 33\% from 2012 to 2016. Only public hospitals reported reductions, while rates in publicly reimbursed private hospitals increased by $12 \%$ in the same period. Compared with the other Regional Health Authorities, the reduction of procedures was larger in hospitals in the South-Eastern Norway Regional Health Authority. This coincides in time with strong recommendations to the surgical departments from 2012 and more restrictive contract terms from 2015. We also observed an unexplainable regional variation in arthroscopy rates. Results from the present study suggest that poorly documented and potentially harmful surgical practices can be reduced through both professional guidance and administrative regulations.

Contributors RH, OT, JIB, MAR and AKA conceptualised the study. DN searched and provided data from the National Patient Registry. AKA provided expertise on arthroscopic procedures and coding. $\mathrm{RH}$ analysed the data and did the statistical analysis. RH prepared the initial manuscript draf, which was subsequently edited by all authors. All authors read and approved the final manuscript and agreed to submission. $\mathrm{RH}$ is the guarantor.

Funding The authors have not declared a specific grant for this research from any funding agency in the public, commercial or not-for-profit sectors.

Competing interests None declared.

Patient consent Not required.

Provenance and peer review Not commissioned; externally peer reviewed.

Data sharing statement № additional data are available.

Open access This is an open access article distributed in accordance with the Creative Commons Attribution Non Commercial (CC BY-NC 4.0) license, which permits others to distribute, remix, adapt, build upon this work non-commercially, and license their derivative works on different terms, provided the original work is properly cited and the use is non-commercial. See: http://creativecommons.org/ licenses/by-nc/4.0/

(C) Article author(s) (or their employer(s) unless otherwise stated in the text of the article) 2018. All rights reserved. No commercial use is permitted unless otherwise expressly granted.

\section{REFERENCES}

1. Thorlund JB, Hare KB, Lohmander LS. Large increase in arthroscopic meniscus surgery in the middle-aged and older population in Denmark from 2000 to 2011. Acta Orthop 2014;85:287-92.

2. Tornbjerg SM, Nissen N, Englund M, et al. Structural pathology is not related to patient-reported pain and function in patients undergoing meniscal surgery. Br J Sports Med 2017;51.

3. Guermazi A, Niu J, Hayashi D, et al. Prevalence of abnormalities in knees detected by MRI in adults without knee osteoarthritis: population based observational study (Framingham Osteoarthritis Study). BMJ 2012:345:e5339.

4. Hare KB, Vinther JH, Lohmander LS, et al. Large regional differences in incidence of arthroscopic meniscal procedures in the public and private sector in Denmark. BMJ Open 2015;5:e006659.
5. Sihvonen R, Paavola M, Malmivaara A, et al. Arthroscopic partial meniscectomy versus sham surgery for a degenerative meniscal tear. N Engl J Med 2013;369:2515-24.

6. Herrlin S, Hållander M, Wange P, et al. Arthroscopic or conservative treatment of degenerative medial meniscal tears: a prospective randomised trial. Knee Surg Sports Traumatol Arthrosc 2007;15:393-401.

7. Moseley JB, O'Malley K, Petersen NJ, et al. A controlled trial of arthroscopic surgery for osteoarthritis of the knee. N Engl J Med 2002;347:81-8.

8. Katz JN, Brophy RH, Chaisson CE, et al. Surgery versus physical therapy for a meniscal tear and osteoarthritis. $N$ Engl J Med 2013;368:1675-84.

9. Kise NJ, Risberg MA, Stensrud S, et al. Exercise therapy versus arthroscopic partial meniscectomy for degenerative meniscal tear in middle aged patients: randomised controlled trial with two year follow-up. BMJ 2016;354:3740.

10. Yim JH, Seon JK, Song EK, et al. A comparative study of meniscectomy and nonoperative treatment for degenerative horizontal tears of the medial meniscus. Am J Sports Med 2013;41:1565-70.

11. Kirkley A, Birmingham TB, Litchfield RB, et al. A Randomized Trial of Arthroscopic Surgery for Osteoarthritis of the Knee. N Engl J Med Overseas Ed 2008;359:1097-107.

12. Thorlund JB, Juhl CB, Roos EM, et al. Arthroscopic surgery for degenerative knee: systematic review and meta-analysis of benefits and harms. Br J Sports Med 2015;49:1229-35.

13. Khan M, Evaniew N, Bedi A, et al. Arthroscopic surgery for degenerative tears of the meniscus: a systematic review and metaanalysis. CMAJ 2014;186:1057-64.

14. Beaufils $P$, Becker R, Kopf $\mathrm{S}$, et al. Surgical management of degenerative meniscus lesions: the 2016 ESSKA meniscus consensus. Knee Surgery, Sports Traumatology, Arthroscopy 2017;25:335-46.

15. Abrams GD, Frank RM, Gupta AK, et al. Trends in meniscus repair and meniscectomy in the United States, 2005-2011. Am J Sports Med 2013;41:2333-9.

16. Hamilton D, Howie C. Why do rates of knee arthroscopy differ between England and Scotland? Thebmi 2015;1::350.

17. Lazic S, Boughton O, Hing C, et al. Arthroscopic washout of the knee: a procedure in decline. Knee 2014;21:631-4.

18. Harris IA, Madan NS, Naylor JM, et al. Trends in knee arthroscopy and subsequent arthroplasty in an Australian population: a retrospective cohort study. BMC Musculoskelet Disord 2013;14:1-6.

19. Mattila VM, Sihvonen R, Paloneva J, et al. Changes in rates of arthroscopy due to degenerative knee disease and traumatic meniscal tears in Finland and Sweden. Acta Orthop 2016;87:5-11.

20. Muheim LLS, Senn O, Früh M, et al. Inappropriate use of arthroscopic meniscal surgery in degenerative knee disease. Acta Orthop 2017;88:550-5.

21. Birkmeyer JD, Reames BN, McCulloch P, et al. Understanding of regional variation in the use of surgery. Lancet 2013;382:1121-9.

22. Bohensky MA, Sundararajan V, Andrianopoulos N, et al. Trends in elective knee arthroscopies in a population-based cohort, 20002009. Med J Aust 2012;197:399-403.

23. Mitchell JM. Effect of physician ownership of specialty hospitals and ambulatory surgery centers on frequency of use of outpatient orthopedic surgery. Arch Surg 2010;145:732-8.

24. Pihl K, Roos EM, Nissen N, et al. Over-optimistic patient expectations of recovery and leisure activities after arthroscopic meniscus surgery. Acta Orthop 2016;87:615-21.

25. Arterburn $D$, Wellman $R$, Westbrook $E$, et al. Introducing decision aids at Group Health was linked to sharply lower hip and knee surgery rates and costs. Health Aff 2012;31:2094-104.

26. Skou ST, Roos EM. Good Life with osteoArthritis in Denmark (GLA:D ${ }^{T M}$ ): evidence-based education and supervised neuromuscular exercise delivered by certified physiotherapists nationwide. BMC Musculoskelet Disord 2017;181:72. 